\title{
PEDAGOGICAL PROFILE OF THE RELATIONSHIP BETWEEN PARENTS AS PRISONERS AND THE CHILD'S BEHAVIOUR
}

\author{
A. Stoykov*, S. Dinchiyska, S. Todorov \\ Department of Social Activities, Faculty of Medicine, Trakia University, Stara Zagora, Bulgaria
}

\begin{abstract}
This article deals with the relationship between parents (fathers) serving imprisonment and their children. The study aims at finding out whether there is a correlation between the father's negative behavior and its impact on his own children. Fathers serving imprisonment in Stara Zagora Prison and their children took part in the study. Complex methods were used, i.e. diagnostic interview carried out with the fathers (prisoners), class teachers and pedagogical advisors; observation of the children's behavior in real pedagogical environment; document analysis; mathematical and statistical methods for processing empirical data. The criterion reference study scheme included child's behavior type (aggressive, positive, combined) and types of aggression (verbal, physical, combined, auto-aggression). The empirical information allows elaborating recommendations with reference to the individual work with children whose parents are in prison.

The focus of the study is not the parent -child biological relation but the role of the family as a social environment with distorted value system.
\end{abstract}

Key words: parent (prisoner), child (student), aggression, behavior, pedagogical profile

\section{INTRODUCTION}

Nowadays, there are many studies and theoretical discussions aimed at overcoming the drawbacks in the existing penitentiary institutions. In the European countries, the need of adopting a modern "European prison model" by which to overcome these deficiencies, is being discussed.

One of the main features of the European prison model is said to be the possibility for protection of the prisoner's family life and personal relations, an important aspect of which is the parent (prisoner)- child relation.

The results of the studies conducted in a number of EU-member states show that the most important indicator for the meaning of the "imprisonment" is the extent to which convicts re-socialize in society after serving their sentences. A significant number of the social workers in the EU penitentiary systems, including Bulgaria, point out as their main task prevention and re-socialization, as well as the

*Correspondence to: Assoc. Prof. Anton Stoykov, PhD, Department of Social Activities, Faculty of Medicine, Trakia University, 11 Armejska str., 6000 Stara Zagora, Tel.: 042/644417, Mobile: 0877 331 551,e-mail: stoykov70@abv.bg implementation of programmes aimed at promoting these processes.

Reviewing re-socialization of the convicts in penitentiary institutions is a multi-layered problem. This implies the use of a multidisciplinary approach to the problem itself. This phenomenon is studied by sociology, criminology, victimology, cultural studies, psychology, pedagogy. Mezzo-factor environment of the penitentiary institutions is seen as the main determinant of resocialization of the convicts. Depriving the convicts of their ability to make decisions related to their everyday life independently, reduces their adaptive capacity and results in atrophy of their social habits. Living permanently in a criminal environment creates emotional and psychological isolation. Condemnation by the public further reduces the contacts with the outside world and results in a state of depression, feeling of doomness and apathy. In this regard, of particular concern stands out the impact of these negative states onto the children of convicts.

The aim of the study is to determine the specifics of the relationship between children 
and parents deprived of freedom, and approval of the appropriate models for social work.

\section{Tasks:}

1. Elaborating a socio-cultural characterization of the convict's personality at the place of the convict establishment;

2. Determining the social and pedagogical profile of the persons deprived of freedom, aged 20-35 in Stara Zagora Prison;

3. Analysis of the social work models at the places of imprisonment;

4. Analysis of the most significant factors for re-socialization of convicts;

5. Characterization of the changes in the convict's value system, under the impact of various social work models.

\section{MATERIALS AND METHODS}

The specifics of the study required use of complex methods:

Theoretical analysis;

Documentation analysis;

Questionnaire "Prisoners' internal value systems";

Expert assessment;

Episodic observation;

Tests for assessment of the social intelligence;

Methods for diagnostics of the emotional empathy level;

Tests to assess social anxiety

\section{Criteria and indicators}

Prisoners to realize their own anti-social acts and behavior

Prisoners to realize the need to change their own lives;

Prisoners to realize the need of positive change in their behavior as parents;

Behavior correction;

Developing patterns of behavior in various life situations;

Criteria are assesses according to a four-level scale: high, moderate, low, none

\section{Stages of the Research Study}

The study was carried out in 3 stages: ascertaining, formative and conclusive

In the ascertaining stage, the problem was thoroughly analyzed.

This stage included studying the theoretical sources related to the problem, discussions with the social work inspectors at the places of imprisonment and carrying out the activities related to re-socialization of the convicts, content-analysis of the records for individual educational work with the convicts, assessment of the social status of the persons taking part in the experimental work on the basis of the existent information, empirical study, including a questionnaire with the convicts titled "Prisoners' internal value systems", expert assessment, episodic observations, the level of social intelligence, the emotional empathy and the anxiety level were assessed.

It was found out that at present the traditionally accepted classification for social work models is as follows:

- Psychologically oriented

- Socially oriented

- Complex oriented

- Management oriented

The formative stage is focused onto social and pedagogical work with the people from the experimental group, including approbation of a block of models for social work on side of the social work inspectors and the people included in the project team.

For the conclusive stage, objective analysis and systematization of the results was planned, including processing of theoretical and experimental data, summary of the results, promoting the results by holding a round table meeting and other scientific forums. Analysis of the empirical results was planned to take place at 2 stages: interim and final.

\section{DISCUSSION}

Re-socialization in the broad sense is understood as a process of developing social norms and cultural values, undeveloped or not adequately developed earlier by the individual, or updated in connection with a newer stage of the social development. In this study, resocialization is used in its narrow sense, i.e. meaning developing values and norms by the individual which differ from those developed earlier.

Within this meaning, re-socialization can be considered also as an initial socialization since in the course of re-socialization the reality is perceived in a different way. In this regard, resocialization constitutes a change in the system and structure of the values and models of behaviour earlier developed and also further development of values other than the former ones.

The nature of the social work at the places of imprisonment is socially pedagogical and socially educational. It is mainly focused on achieving personality traits change which is associated with the readiness for adopting a lawful and socially acceptable lifestyle. Achieving this change is impossible without overcoming the deficiencies in the process of 
socialization of the individual, most often resulting from the lack of support on side of family and school, the closest environment and other institutions.

In the existent penitentiary system in our country, imprisonment is implemented through three main activities: socio - educational, regime and security and production and business oriented. Each activity has its specific purposes with regard to the overall purpose of the penalty.

The activities as part of the social works can be presented in three provisional classification groups:

- Activities related to rendering administrative support to prisoners

- Activities related to social and pedagogical intervention by the help of which the convicts develop the values and models of a socially acceptable behavior and improve their social competence. A bigger part of these activities are implemented also by the social work models directed to overcoming the deficiencies in the process of socialization.

- Activities related to rendering specialized psychological support.

The main problems which go together with the social inclusion of the convicts and which appear to be a main hindrance for their complete socialization are:

1. The low educational status

2. No professional qualification

3. No work experience

The above-mentioned suggests approbation of models for social work in the penitentiary system considering all above-listed specifics of the places of imprisonment as well as the problems which hinder the successful resocialization of those serving imprisonment and are related to the existing deficiencies in the process of their socialization.

\section{RESULTS /Analysis of the Empirical Data at the Interim Stage/}

The study involved 30 men deprived of freedom aged 21-35 who were also parents of children aged 4 to 14 .

At the interim stage of the study, a few empirical blocks were established: values of the convicts, level of anxiety, social empathy, pedagogical profile.
A special attention is paid to the pedagogical profile of the parent (prisoner). The study showed that there is a correlation between the values of the prisoners and their behavior towards their own children.

For $90 \%$ of the persons involved in the study, family was a main value. For the rest $10 \%$, most important was work. All of them shared the opinion that the most important members of the family are the children. Those people also pointed out that they would like to set a good example for children's behavior.

In the opinion of the pedagogical advisors, both parents and children are exceptionally adaptive and purposefully adjust their opinion in accordance with the expectations of the researcher. The motivation for such mimicry is the personal benefit of presenting themselves in a better aspect. Even their passionately claimed religiosity can be interpreted as intentional and demonstrative in a bigger part of the cases.

Quite different is the situation with the children involved in the study. The main part of the information was collected by the expert assessment of the school psychologists and pedagogical advisors. As a rule, we did not talk directly to the children since for them we were strangers.

Children did not experience negative feelings such as shame or embarrassment from the fact that their fathers were in prison,. Some of them were even proud of this fact. Apparently, in their community, imprisonment is not considered antisocial. We also found out another aspect of the parent (prisoner)-male child relation. It turned out that 14 -year old boys take over the "business" of their imprisoned fathers, i.e. procuring for prostitution, drug-dealing, cigarette smuggling.

From pedagogical point of view, interesting is the fact that in emotional aspect, boys tend to be more vulnerable. In the opinion of the experts, they show higher anxiety levels and emotional bond with their fathers serving imprisonment. The reason might be the bond between parents and children of the same gender.

\section{CONCLUSION}

Since the study is in its interim stage, the results obtained cannot be deemed final. They have relative nature and pose the necessity of individual work at school. 